\title{
NOTE \\ Simplified Description of Adsorption Breakthrough Curves of 1,1-Dichloro-1-fluoroethane (HCFC-141b) on Activated Carbon with Temperature Effect
}

Recovery of HCFC-141b, used as a major alternative solvent and foam-blowing agent for CFC s in industrial applications, has received great attention due to its gradual phase out. This paper describes an investigation of the adsorption breakthrough of HCFC-141b vapor on a commercial activated carbon. A simple theoretical model developed by $\mathrm{Y}$ oon and $\mathrm{N}$ elson was applied to investigate the breakthrough behavior of HCFC-141b on an activated carbon column. The values of parameters $k^{\prime}$ (a rate constant) and $\tau$ (the time required for $50 \%$ adsorbate breakthrough) in the Yoon and Nelson model were determined at four different concentration levels (i.e., 399, 734, 1139, and 1954 ppmv) and five temperature ranges (i.e., 283, 293, 298, 303, and $313 \mathrm{~K}$ ), respectively. These values were used to calculate the entire $(0-100 \%)$ breakthrough curve (plot of percentage breakthrough versus time) regarding the adsorption of HCFC-141b on activated carbon columns. It was found that the calculated theoretical breakthrough curves are in high agrement with the corresponding experimental data. Also, the rate constant $k^{\prime}$ can be reasonably represented by the empirical Arrhenius equation. The results obtained are applicable for the scale-up design of adsorption columns in the HCFC adsorption on activated carbon adsorbent. $\odot 1999$ Academic Press

Key Words: adsorption breakthrough; HCFC-141b; activated carbon; temperature effect.

\section{INTRODUCTION}

Recently, under the terms of the Montreal Protocol in Substances that Deplete the Ozone Layer, the production and use of hydrochlorofluorocarbons (HCFCs) such as 1,1-dichloro-1-fluoroethane (HCFC-141b) will gradually be phased out by the year 2030 or earlier (1). Because they have physicochemical properties similar to those of chlorofluorocarbons (CFCs) and relatively low ozone depletion potential (ODP), HFCs are currently considered excellent interim substitutes for CFCs in industrial applications (2). HCFC-141b, one of the most widely used HCFCs, is currently used as a popular substitute for CFC-113, which was the cleaning agent employed in the electronic and precision-machining industries, and is an excellent replacement for CFC-11, which was the foaming agent in the manufacturing of polyurethane insulation (3). Therefore, it is necessary to adopt the so-called maximum achievable control technology (e.g., adsorption) for the emission control and recovery of HCFC-141b.

Fixed-bed adsorption has been applied widely in separation and recovery of vapors of volatile organic compounds (VOCs) (4). In general, it has been recognized that activated carbon is the most practical adsorbent for the separation applications due to its large internal surface area and pore volume (5). To design such an adsorption process, it is important to understand the thermodynamic characteristics between the adsorbent and the adsorbate. In addition, knowledge of adsorption kinetics or dynamic behavior in a fixed bed is also valuable in calculating adsorption separation processes. However, the numerical computation of mass and heat balance equations for each granular adsorbent, in addition to the balances for the bed, greatly complicates the task regarding the breakthrough curve (5).

Many theoretical or empirical equations have been proposed for modeling the breakthrough curves in fixed-bed adsorption (6). Measured breakthrough times (i.e., times to reach defined effluent concentrations) for adsorbate removal from flowing air by activated charcoal have been fitted to the modified Wheeler equation (7), the Mecklenburg equation (8), and the Yoon and Nelson equation $(9,10)$. Of these, the Wheeler equation was derived originally for catalysis with bed poisoning, and the Mecklenburg equation was proposed for predicting gas mask filtration. These theoretical approaches are relatively complicated and not entirely satisfactory (9). The Yoon and Nelson equation was developed by a simple model addressing the adsorption and the breakthrough of adsorbate vapors or gases with respect to activated charcoal. The Yoon and Nelson model not only is less complicated than the Wheeler and Mecklenburg equations but also requires no detailed data concerning the characteristics of the adsorbate of interest, the type of activated charcoal, or the physical properties of the adsorption bed. That is, the applications of both modified Wheeler and Mecklenburg equations require the values of a number of parameters, which are not easy to obtain or estimate. Moreover, the Yoon and Nelson model has been successfully applied to describe the breakthrough curves for different organic adsorbate vapors at several different adsorbate concentrations. It was noted that the new model agrees with experimental data over the entire range of adsorbate breakthrough percentages (i.e., 0-100\%), whereas the breakthrough curves derived by the Wheeler and Mecklenburg equations have approximately the same shape as the corresponding experimental curves for $0-40 \%$ breakthrough $(9,10)$.

In contrast to the successful application of these theoretical or empirical equations to the breakthrough behavior in respirator cartridges with coconutbased charcoal at constant room temperature, there appears to be relatively little information in the literature concerning the effect of the adsorption temperature on the breakthrough behavior and adsorption kinetics. Therefore, the purpose of this paper is to apply a simple model with two parameters suggested by Yoon and Nelson for modeling the breakthrough curves of HCFC-141b through beds of activated carbon with the consideration of the effect of temperature.

\section{MATERIALS AND METHODS}

The laboratory adsorption system has been described previously (3). HCFC$141 \mathrm{~b}$ vapor, constantly generated from a thermostat impinger apparatus, was diluted with dehumidified dry air for all experiments. Activated carbon from coconut with mesh numbers of 20/30 (average particle diameter of $0.718 \mathrm{~mm}$ ) (Taipei Chemical Co., Taipei, Taiwan) was dried at $378 \mathrm{~K}$ in a vacuum oven for at least $24 \mathrm{~h}$ before testing. Its main physical characteristics, as measured by an automatic volumetric analyzer (ASAP 2000, Micromeritics) using ni- 


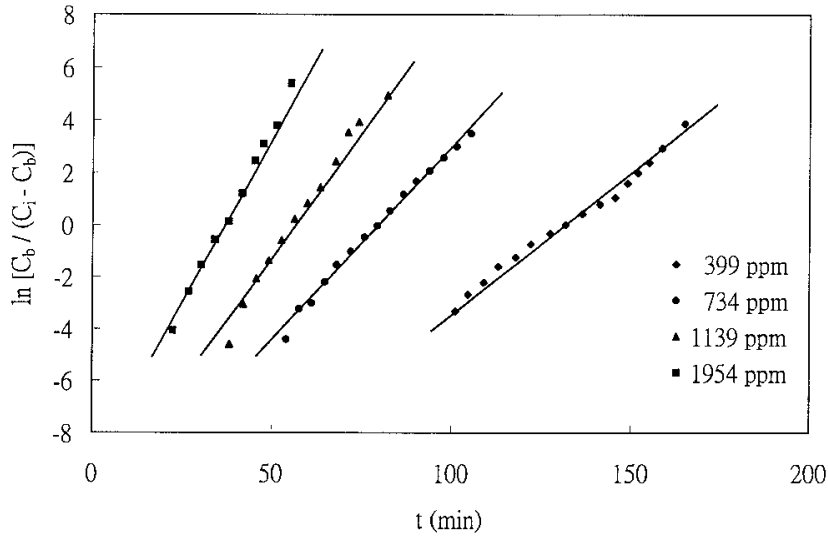

FIG. 1. Typical plots of $\ell \mathrm{n}\left[C_{\mathrm{b}} /\left(C_{\mathrm{i}}-C_{\mathrm{b}}\right)\right]$ versus sampling time $(t)$ for HCFC-141b adsorption on activated carbon at $293 \mathrm{~K}$ (symbols: experimental data; solid lines: calculated from Eq. [4]).

trogen adsorption at $77 \mathrm{~K}$, are as follows: BET surface area of $994 \mathrm{~m}^{2} / \mathrm{g}$, average pore diameter of $15.6 \AA$, and total pore volume of $0.508 \mathrm{~cm}^{3} / \mathrm{g}$. The experimental runs were performed at HCFC-141b concentration levels of 399-1954 ppmv and adsorption temperatures of 283, 293, 298, 303, and 313 $\mathrm{K}$, which were maintained by a refrigerated circulating-water bath $( \pm 0.1 \mathrm{~K}$ accuracy). The feed, consisting of a ca. $2900 \mathrm{~cm}^{3} / \mathrm{min}$ gas stream with HCFC-1414b vapor in air, was composed by means of a mass flow controller (Model HCFC, Hastings Co.) and passed through a fixed-bed adsorption column of $1.5-\mathrm{cm}$ inner diameter. The linear (superficial) velocity of $0.27 \mathrm{~m} / \mathrm{s}$ thus obtained is in the practical range of $0.25-0.50 \mathrm{~m} / \mathrm{s}$ (11). In the present study, breakthrough measurements have been made with a constant contact time of ca. $0.15 \mathrm{~s}$ based on $2.52 \mathrm{~g}$ of activated carbon for all experiments.

A small amount (i.e., $0.1 \mathrm{~cm}^{3}$ ) of the effluent sample of HCFC-141b vapor in air was taken into a gas-tight microsyringe at suitable time intervals (i.e., 2-10 min) during breakthrough measurements. The concentrations of HCFC$141 \mathrm{~b}$ were measured by a gas chromatograph with a flame ionization detector (FID). Analytical instruments and conditions were described previously (3). When the effluent concentration of the adsorbate HCFC-141b reached its specified influent concentration (i.e., 100\% of breakthrough), the concentration measurement of the effluent gas was stopped.

As an applicable approximation, the breakthrough analysis is described as follows according to the model of Yoon and Nelson (9). Consider the gas adsorption kinetics in the fixed bed of adsorbent. Some of the adsorbate molecules are adsorbed on adsorption sites and others pass through the adsorbent bed. Yoon and Nelson (9) introduced $Q$ as the probability for adsorption and $P$ as the probability for breakthrough. The relationship between $Q$ and $P$ is therefore

$$
P=1-Q=C_{\mathrm{b}} / C_{\mathrm{i}},
$$

where $C_{\mathrm{b}}$ and $C_{\mathrm{i}}$ are the breakthrough (effluent) concentration $\left(\mathrm{kg} / \mathrm{m}^{3}\right)$ and influent concentration $\left(\mathrm{kg} / \mathrm{m}^{3}\right)$ of the adsorbate, respectively. Since the rate of adsorption is proportional to the rate of molecular collisions with unoccupied adsorption sites (12), it is reasonably assumed that the rate of change in the breakthrough concentration, $d C_{\mathrm{b}} / d t$, is proportional to $C_{\mathrm{b}}$ and to the number of adsorptive sites. Therefore

$$
-d Q / d t=k^{\prime} Q(1-Q),
$$

where $k^{\prime}$ is a rate constant $\left(\mathrm{min}^{-1}\right)$. To obtain an explicit expression, the solution of the differential equation [2] is solved by using the integration approach (9).

$$
\ell \mathrm{n} \frac{Q}{1-Q}=k^{\prime}(\tau-t)
$$

where $\tau$ is the time required to obtain $50 \%$ breakthrough (i.e., $Q=0.5$ ). Rearranging Eq. [3], one obtains an expression for the breakthrough (sampling) time $(t)$ in terms of the influent concentration $\left(C_{\mathrm{i}}\right)$ and the breakthrough concentration $\left(C_{\mathrm{b}}\right)$ :

$$
t=\tau+\frac{1}{k^{\prime}} \ln \frac{C_{\mathrm{b}}}{C_{\mathrm{i}}-C_{\mathrm{b}}} .
$$

According to Eq. [4], the value of $k^{\prime}$ can be obtained from the slope of the plot $\ell$ n $\left[C_{\mathrm{b}} /\left(C_{\mathrm{i}}-C_{\mathrm{b}}\right)\right]$ versus breakthrough time $t$, and the value of $\tau(50 \%$ breakthrough time) can be determined as the time at $Q=0.5$ (i.e., $C_{\mathrm{b}}=C_{\mathrm{i}} / 2$ ). Following the determination of $k^{\prime}$ and $\tau$, one may generate the complete breakthrough curve for a given set of experimental conditions by applying Eq. [4]. Yoon and Nelson (9) further introduced the following relationship:

$$
k=k^{\prime} \tau,
$$

where $k$ is a proportionality constant for a given adsorbate and specified type of adsorbent. They indicated that $k$ is independent of adsorbate concentration and flow rate. On the other hand, both $k^{\prime}$ and $\tau$ are dependent on the concentration of the adsorbate and the flow rate (9).

\section{RESULTS AND DISCUSSION}

In this study, the relationship between sampling time $(t)$ and breakthrough fraction (i.e., $C_{\mathrm{b}} / C_{\mathrm{i}}$ ) was investigated for each concentration of HCFC-141b at various temperatures. It should be noted that breakthrough fraction is a

\begin{tabular}{|c|c|c|c|c|c|}
\hline $\begin{array}{l}\text { Concentration } \\
\text { (ppmv) }\end{array}$ & $\begin{array}{c}\text { Temperature } \\
\text { (K) }\end{array}$ & $\begin{array}{c}k^{\prime} \\
\left(\min ^{-1}\right)\end{array}$ & $\begin{array}{c}\tau \\
(\min )\end{array}$ & $k$ & $R^{2}$ \\
\hline \multirow[t]{5}{*}{399} & 283 & 0.0918 & 147.7 & 13.562 & 0.9932 \\
\hline & 293 & 0.1022 & 131.3 & 13.414 & 0.9894 \\
\hline & 298 & 0.1076 & 112.1 & 12.058 & 0.9837 \\
\hline & 303 & 0.1172 & 106.5 & 12.482 & 0.9944 \\
\hline & 313 & 0.1214 & 84.6 & 10.270 & 0.9949 \\
\hline \multirow[t]{5}{*}{734} & 283 & 0.1448 & 92.1 & 13.338 & 0.9883 \\
\hline & 293 & 0.1499 & 80.0 & 11.995 & 0.9921 \\
\hline & 298 & 0.1526 & 70.9 & 10.814 & 0.9886 \\
\hline & 303 & 0.1599 & 66.9 & 10.704 & 0.9965 \\
\hline & 313 & 0.1723 & 56.0 & 9.642 & 0.9901 \\
\hline \multirow[t]{5}{*}{1139} & 283 & 0.1933 & 59.8 & 11.561 & 0.9925 \\
\hline & 293 & 0.2144 & 56.3 & 12.070 & 0.9874 \\
\hline & 298 & 0.2202 & 52.9 & 11.659 & 0.9985 \\
\hline & 303 & 0.2253 & 49.0 & 11.034 & 0.9953 \\
\hline & 313 & 0.2433 & 42.9 & 10.431 & 0.9926 \\
\hline \multirow[t]{5}{*}{1954} & 283 & 0.2558 & 39.9 & 10.218 & 0.9963 \\
\hline & 293 & 0.2770 & 36.6 & 10.142 & 0.9965 \\
\hline & 298 & 0.2909 & 35.5 & 10.048 & 0.9689 \\
\hline & 303 & 0.3075 & 33.0 & 10.160 & 0.9816 \\
\hline & 313 & 0.3444 & 28.6 & 9.863 & 0.9945 \\
\hline
\end{tabular}

TABLE 1

Values of the Theoretical Parameters $k^{\prime}, \tau$, and $k$ for Adsorption of HC FC -141b on Activated C arbon at V arious Temperatures and Inlet Concentrations ${ }^{a}$

\footnotetext{
${ }^{a}$ Mass of activated carbon used in this study is $2.52 \pm 0.01 \mathrm{~g}$.
} 


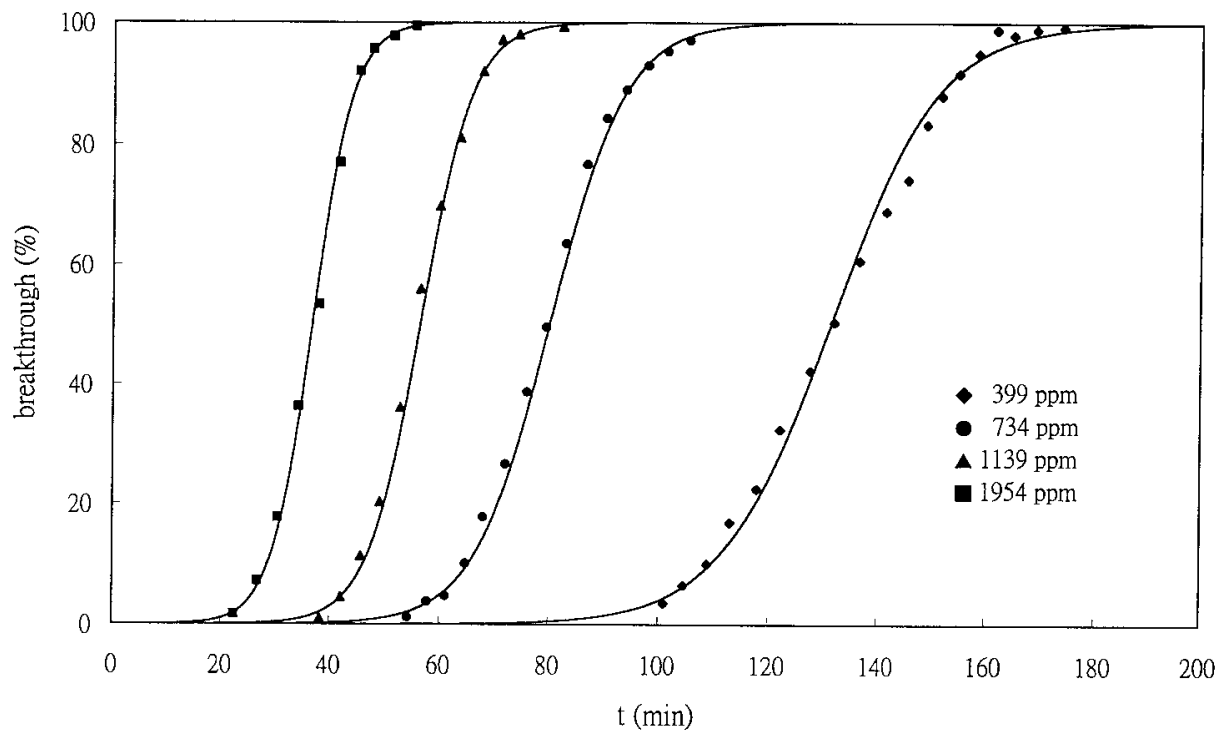

FIG. 2. Typical breakthrough curves of HCFC-141b adsorption on activated carbon at various concentrations and $293 \mathrm{~K}$ (symbols: experimental data; solid lines: calculated from Eq. [4]).

function of sampling time according to Eq. [4]. A typical illustration of the application of Eq. [4] is depicted in Fig. 1 based on the experimental data of breakthrough for HCFC-141b in the concentration range 399-1954 ppmv at 293 K. As predicted by the Yoon and Nelson model of Eq. [4], the plots of Fig. 1 yield straight lines with a slope of $k^{\prime}$ and intercept of $-k$. As shown in Fig. 1 , the model appears to fit the experimental data reasonably well. Thus, the rate constant $k^{\prime}$ and $50 \%$ breakthrough time $\tau$ can be calculated by fitting a straight line. The least-squares method has been used to give these values as listed in Table 1. The values of $k$, computed from Eq. [5], are also listed in Table 1. As expected from the Yoon and Nelson model $(9,10)$, both $k^{\prime}$ and $\tau$ are dependent on the adsorbate inlet concentration. As shown in Table 1, the rate constant $k^{\prime}$ increases with increasing adsorbate inlet concentration, whereas the $50 \%$ breakthrough time $\tau$ decreases. Table 1 also presents the values of $k^{\prime}$ and $\tau$ at various adsorption temperatures at adsorbate concentrations of 399-1954 ppmv. It was found that $k^{\prime}$ and $\tau$ are significantly influenced by the adsorption temperature; i.e., the value of $k^{\prime}$ increases with increasing adsorption temperature, while the value of $\tau$ decreases. This is consistent with the results based on the Yoon and Nelson analysis, namely, that the calculated $10 \%$ breakthrough times for several solvents were diminished between 1 and $10 \%$ with each $10^{\circ} \mathrm{C}$ rise in temperature (13). The value of $k$, on the other hand, seems to be independent of the adsorbate inlet concentration and adsorption temperature, as shown in Table 1. It is noted that the preceding results concerning the concentration effects were consistent with those of Yoon and Nelson's experiments $(9,10)$. The mean and standard deviation values of $k$ were thus determined to be 11.273 and 1.249 , respectively.

Following the determination of the values of $k^{\prime}$ and $\tau$, the complete breakthrough curves can be generated for a given set of experimental conditions by substituting the determined values of $k^{\prime}$ and $\tau$ (Table 1) into Eq. [4]. The calculated theoretical curves are compared with the corresponding experimental data in Fig. 2. It is demonstrated that the agreement between the Yoon and Nelson model and the experimental data is high in the present study. This is reasonable if one notes that the solid lines in Fig. 1 represent the lines of best fit, which have good correlation $\left(R^{2}=0.97-0.99\right.$, as shown in Table 1).

Using the Arrhenius relationship as follows (14), one may examine the effect of adsorption temperature $(T)$ on the rate constant $\left(k^{\prime}\right)$.

$$
\ell \mathrm{n} k^{\prime}=-E /(R T)+\ell \mathrm{n} k_{0},
$$

where $k_{0}$ is a constant $\left(\mathrm{min}^{-1}\right), E$ is the activation energy $(\mathrm{J} / \mathrm{mol}), R$ is the ideal gas law constant $(=8.314 \mathrm{~J} /(\mathrm{mol} \mathrm{K}))$, and $T$ is the adsorption temperature $(\mathrm{K})$. A plot of $\ell \mathrm{n} k^{\prime}$ versus $1 / T$ resulted in a straight line with a slope of $-E / R$ and an intercept of $\ell \mathrm{n} k_{0}$. Figure 3 presents the Arrhenius plots of the rate constant $k^{\prime}$ versus the adsorption temperature $T$ for the adsorption of HCFC-141b on activated carbon. In all cases, reasonably good linear plots were obtained with correlation coefficients $\left(R^{2}\right)$ of $0.9648,0.9351,0.9849$, and 0.9846 for the adsorbate concentrations of 399, 754, 1139, and 1954 ppmv, respectively, while the activation energies obtained from the kinetic analysis were 7.21, $4.28,5.46$, and $7.31 \mathrm{~kJ} / \mathrm{mol}$, respectively. As expected, the mean value and standard deviation (i.e., $6.07 \pm 1.46 \mathrm{~kJ} / \mathrm{mol}$ ) of the activation energy of adsorption calculated on the basis of adsorption rate constant $k^{\prime}$ at five temperatures is low compared with the value of the latent heat of vaporization (i.e., $26.03 \mathrm{~kJ} / \mathrm{mol}$ ) of HCFC-141b. This indicates that the adsorption mechanism seems to be predominantly physical in nature in the case of activated carbon.

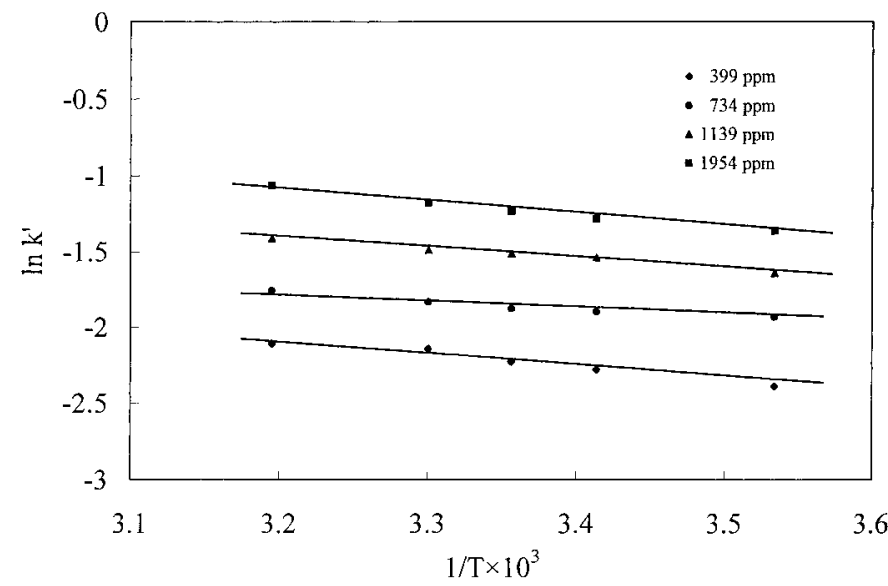

FIG. 3. Arrhenius plots of rate constant $\left(k^{\prime}\right)$ at various adsorbate concentrations of $399,734,1139$, and 1954 ppmv for HCFC-141b adsorption on activated carbon. $R^{2}=0.9648,0.9351,0.9849$, and 0.9846 , respectively. 


\section{CONCLUSIONS}

From the experimental results and data regression, a simple two-parameter (i.e., $k^{\prime}$ and $\tau$ ) model proposed by Yoon and Nelson provided good correlation of the effects of HCFC-141b vapor concentration and adsorption temperature on breakthrough curves of adsorption through an activated carbon column. The parameters calculated from fits of the experimental data with the model were used to generate theoretical breakthrough curves. The calculated theoretical breakthrough curves agree with the corresponding experimental data. It was also found that the rate constant $k^{\prime}$ can be reasonably fitted by the Arrhenius equation.

\section{ACKNOWLEDGMENTS}

The authors acknowledge the financial support of the National Science Council of Taiwan for this project (Contract No. NSC 86-2211-E-041-003).

\section{REFERENCES}

1. Schanffler, S. M., Pollock, W. H., Atlas, E. L., Heidt, L. E., and Daniel, J. S., Geophys. Res. Lett. 22, 819 (1995).

2. Hayman, G. D., and Derwent, R. G., Environ. Sci. Technol. 31, 327 (1997).

3. Tsai, W. T., Chang, C. Y., and Ho, C. Y., Adsorp. Sci. Technol. 16, 67 (1998).

4. Graham, J. R., and Ramaratnam, M., Chem. Eng. 100 (Suppl. 2), 6 (1993).

5. Yang, R. T., "Gas Separation by Adsorption Processes." Butterworths, Stoneham, MA, 1987.

6. Wood, G. O., Am. Ind. Hyg. Assoc. J. 48, 703 (1987).
7. Wheeler, A., and Robell, A., J. Catal. 13, 299 (1969).

8. Klotz, I. M., Chem. Rev. 39, 241 (1946).

9. Yoon, Y. H., and Nelson, J. H., Am. Ind. Hyg. Assoc. J. 45, 509 (1984).

10. Yoon, Y. H., and Nelson, J. H., Am. Ind. Hyg. Assoc. J. 45, 517 (1984).

11. Parmele, C. S., O’Connell, W. L., and Basdekis, H. S., Chem. Eng. 86(12), 58 (1979).

12. Adamson, A. W., "Physical Chemistry of Surfaces," 5th ed. Wiley, New York, 1990.

13. Yoon, Y. H., and Nelson, J. H., Am. Ind. Hyg. Assoc. J. 35, 514 (1976).

14. Smith, J. M., "Chemical Engineering Kinetics," 3rd ed. McGraw-Hill, New York, 1981.
W. T. Tsai*
C. Y. Chang $\dagger^{11}$
C. $\mathrm{Y}$. $\mathrm{Ho} \dagger$
L. Y. Chent

*Department of Environmental Engineering and Health

Chia Nan College of Pharmacy and Science

Tainan 717, Taiwan

$\dagger$ Graduate Institute of Environmental Engineering

National Taiwan University

71 Chou-Shan Road

Taipei 106, Taiwan

Received November 30, 1998; accepted February 25, 1999

\footnotetext{
${ }^{1}$ To whom correspondence should be addressed. E-mail: cychang3@ ccms.ntu.edu.tw.
} 